\title{
Cutis marmorata telangiectatica congenita with skin ulceration: a rare benign skin vascular malformation
}

\author{
Deng Jia, ${ }^{1}$ Victor Samuel Rajadurai, ${ }^{2}$ Suresh Chandran ${ }^{2,3,4,5}$
}

'Department of Pediatrics, National University Singapore Yong Loo Lin School of Medicine, Singapore, Singapore ${ }^{2}$ Department of Neonatology, KK Women's and Children's Hospital, Singapore, Singapore ${ }^{3}$ Department Neonatology, Duke-NUS Medical School, Singapore

${ }^{4}$ Department of Neonatology, Yong Loo Lin School of Medicine, National University of Singapore, Singapore ${ }^{5}$ Department of Neonatology, Lee Kong Chian School of Medicine, Singapore

\section{Correspondence to} Professor Suresh Chandran, schandran1312@yahoo.co.uk

Accepted 23 August 2018

\section{DESCRIPTION}

Cutis marmorata telangiectatica congenita (CMTC) is a sporadic congenital disorder characterised by localised or generalised cutaneous vascular anomaly. CMTC was first described in 1922 by Van Lohuizen as a pattern of reticulate erythema and telangiectasia infrequently associated with skin atrophy and/ or ulceration. ${ }^{1}$ It is a rare benign skin lesion that is often apparent at birth with more than 50\% of patients with CMTC having variations of associated defects. Body asymmetry is the most common (33\%) associated anomaly reported. ${ }^{1}$

A 5-day-old female baby was born at term following an uneventful pregnancy. At birth, she weighed $2800 \mathrm{~g}$, and her growth profile was appropriate for her age. Her general physical examination was unremarkable except for the appearance of a $3 \times 4 \mathrm{~cm}$ bluish-purple skin lesion over the right knee. The skin lesion had erythematous reticulated appearance at the periphery and ulceration at the centre with subcutaneous atrophy (figure 1). There was no limb asymmetry, other vascular lesions, bony defects or ocular malformations. The ulceration over the right knee healed with local antibiotic ointment application. Her cranial ultrasound and eye examination were normal.

When the infant's reticulated lesion over the right knee was re-examined at 6 months of age, it has markedly reduced in size with an observed puckered scar. There was marked subcutaneous

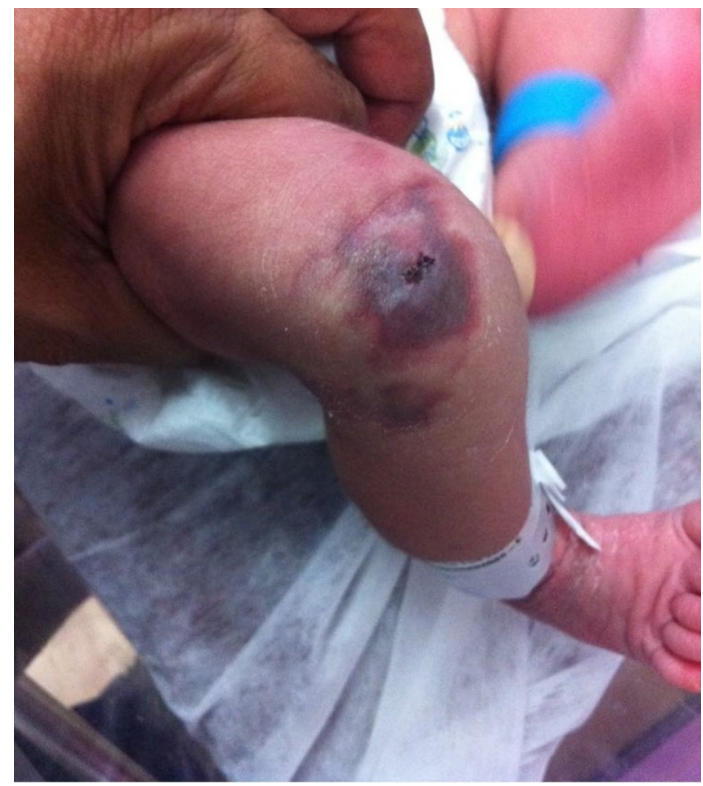

Figure 1 A bluish-purple erythematous plaque with central ulceration over the right knee at birth.

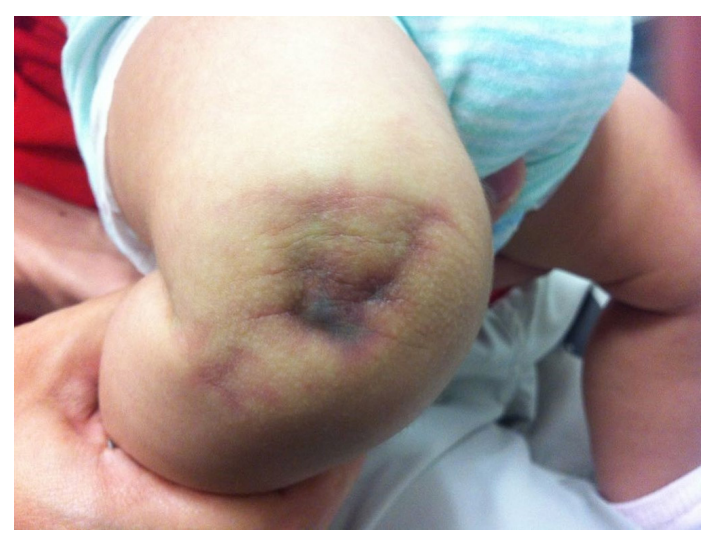

Figure 2 Reticular lesion over the right knee at 6 months of age.

atrophy around the scar (figure 2), and the joint mobility around her knee was unrestricted. At 4 years old, only a fading purplish reticulated lesion with minimal subcutaneous atrophy was observed over the right knee. The child was able to ambulate normally, and she achieved age-appropriate growth parameters and developmental milestones (figure 3).

CMTC is a rare congenital cutaneous anomaly often present at birth, but it can appear later in infancy. There is no sex predilection, and it often affects limbs, seldom the trunk and rarely the face. ${ }^{1}$ The pathogenesis of CMTC remains multifactorial. Homozygous truncating mutation in ARL6IP6 with syndromic form has been reported as a possible genetic cause for CMTC. ${ }^{2}$ However, there is no family history of vascular anomalies in the family of the reported case. Diagnosis of CMTC is clinical, and biopsy is not reliable because of non-specific histological findings. ${ }^{3}$ CMTC may resemble physiological cutis marmorata, a normal physiological skin mottling in cool environments noted in the first few weeks of life, which has a symmetric pattern and disappears on warming. Physiological cutis marmorata may persist in Down syndrome and de Lange syndrome. Neonatal lupus erythematosus can present with both macular and papular telangiectasias in the face and scalp at birth or later and often disappear in 6-8 months of age. Other differential diagnosis of CMTC include port-wine stain and as part of Adam-Oliver syndrome, Bockenheimer syndrome and Klippel-Trenaunay syndrome. Kienast et $a l^{1}$ have suggested diagnostic criteria for diagnosing CMTC. These include the presence of all three major criteria (congenital reticulate erythema, absence of venectasia and unresponsive to local warming) and two of the five minor criteria 


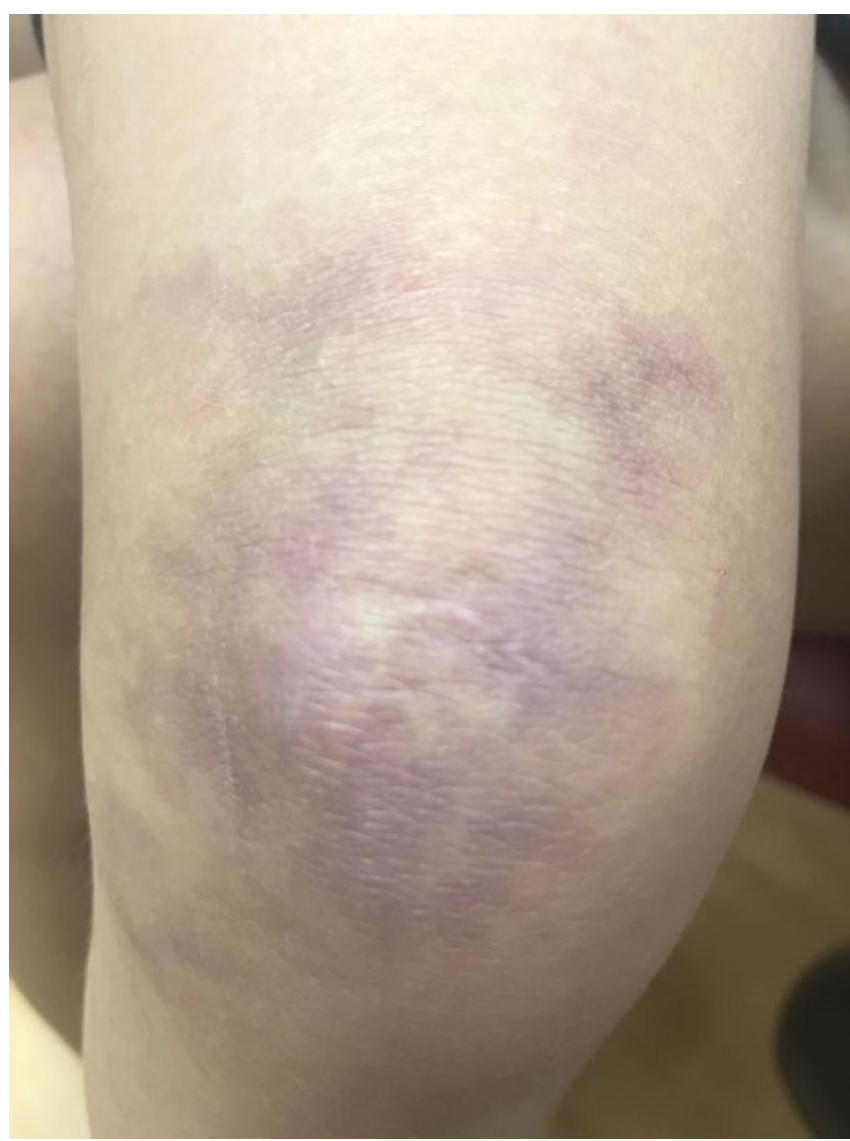

Figure 3 Fade reticular lesion over right knee at 3 years and 10 months of age.

(fading of erythema within 2 years, telengectasia, portwine stain, ulceration and atrophy). Our reported case fulfilled the three major and four minor criteria; therefore, a diagnosis of CMTC can be made.

The prognosis of CMTC is usually good with isolated skin lesion and dermal changes improve during the first 2 years of life as noted in the case reported, and it is expected to disappear completely around puberty.

\section{Learning points}

- Cutis marmorata telangiectatica congenita (CMTC) is a benign rare vascular anomaly often noted in the newborn period. It is a self-limiting disorder without associated anomalies, and its recovery is expected within the first 2 years of life.

- Diagnosis is clinical, and there is no gold standard for diagnosis of CMTC, but there are diagnostic criteria available, ${ }^{1}$ which can be used to distinguish CMTC from cutis marmorata and other vascular malformations.

- Associated anomalies are seen in more than half of the cases of CMTC, and they include mostly limb asymmetry and eye lesions. Less often lesions in the brain, bone, kidney, heart and angiomatous malformations (port-wine stain, haemangioma and lympangioma) are reported.

Acknowledgements We would like to thank Dr Eddy Saputra Leman, PhD, Senior Scientific Editor, Duke-NUS Medical School, 8 College Road \#05-45, Singapore, for editing the manuscript.

Contributors DJ: manuscript preparation and review of literature. VSR and SC: manuscript preparation and finalisation of the manuscript.

Funding The authors have not declared a specific grant for this research from any funding agency in the public, commercial or not-for-profit sectors.

Competing interests None declared.

Patient consent Parental/guardian consent obtained.

Provenance and peer review Not commissioned; externally peer reviewed.

\section{REFERENCES}

1 Kienast AK, Hoeger PH. Cutis marmorata telangiectatica congenita: a prospective study of 27 cases and review of the literature with proposal of diagnostic criteria. Clin Exp Dermatol 2009:34:319-23.

2 Abumansour IS, Hijazi H, Alazmi A, et al. ARL6IP6, a susceptibility locus for ischemic stroke, is mutated in a patient with syndromic Cutis Marmorata Telangiectatica Congenita. Hum Genet 2015;134:815-22.

3 Amitai DB, Fichman S, Merlob P, et al. Cutis marmorata telangiectatica congenita: clinical findings in 85 patients. Pediatr Dermatol 2000;17:100-4.

Copyright 2018 BMJ Publishing Group. All rights reserved. For permission to reuse any of this content visit

http://group.bmj.com/group/rights-licensing/permissions.

BMJ Case Report Fellows may re-use this article for personal use and teaching without any further permission.

Become a Fellow of BMJ Case Reports today and you can:

- Submit as many cases as you like

- Enjoy fast sympathetic peer review and rapid publication of accepted articles

- Access all the published articles

- Re-use any of the published material for personal use and teaching without further permission

For information on Institutional Fellowships contact consortiasales@bmjgroup.com

Visit casereports.bmi.com for more articles like this and to become a Fellow 